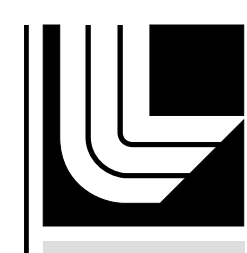

LAWRENCE LIVERMORE NATIONAL LABORATORY

MICROSTRUCTURE IN ADIABATIC SHEAR BANDS IN A PEARLITIC ULTRAHIGH CARBON STEEL

C. K. Syn, D. R. Lesuer, O. D. Sherby

October 9, 2003

Materials Science and Technology 
This document was prepared as an account of work sponsored by an agency of the United States Government. Neither the United States Government nor the University of California nor any of their employees, makes any warranty, express or implied, or assumes any legal liability or responsibility for the accuracy, completeness, or usefulness of any information, apparatus, product, or process disclosed, or represents that its use would not infringe privately owned rights. Reference herein to any specific commercial product, process, or service by trade name, trademark, manufacturer, or otherwise, does not necessarily constitute or imply its endorsement, recommendation, or favoring by the United States Government or the University of California. The views and opinions of authors expressed herein do not necessarily state or reflect those of the United States Government or the University of California, and shall not be used for advertising or product endorsement purposes. 


\title{
Microstructure in adiabatic shear bands in a pearlitic ultrahigh carbon steel
}

\author{
Chol K. Syn ${ }^{1 *}$, Donald R. Lesuer ${ }^{1}$ and Oleg D. Sherby ${ }^{2}$ \\ ${ }^{1}$ syn1@llnl.gov, ${ }^{1}$ lesuer1@llnl.gov, ${ }^{2}$ bulatole@aol.com \\ ${ }^{1}$ Lawrence Livermore National Laboratory, PO Box 808, Livermore, CA 94551, \\ ${ }^{2}$ Deparrtment of Materials Science and Engineering, Stanford University, Stanford, CA 94305
}

\begin{abstract}
Adiabatic shear bands, obtained in compression deformation at a strain rate of $4000 \mathrm{~s}^{-1}$, in a pearlitic $1.3 \% \mathrm{C}$ steel, were investigated. Shear-bands initiated at 55\% compression deformation with the width of the band equal to $14 \mu \mathrm{m}$. Nano-indentor hardness of the shear band was $11.5 \mathrm{GPa}$ in contrast to the initial matrix hardness of $3.5 \mathrm{GPa}$. The high strength of the shear band is attributed to its creation from two sequential events. First, large strain deformation, at a high strain rate, accompanied by adiabatic heating, led to phase transformation to austenite. Second, retransformation upon rapid cooling occurred by a divorced eutectoid transformation. The result is a predicted microstructure consisting of nano-size carbide particles within a matrix of fine ferrite grains. It is proposed that the divorced eutectoid transformation occurs in iron-carbon steels during high rate deformation in ball milling, ball drop tests and in commercial wire drawing.
\end{abstract}

Keywords: Adiabatic shear bands, ultrahigh carbon steel, pearlitic steel, nano-carbides, divorced eutectoid transformation

\section{INTRODUCTION}

Adiabatic shear bands have been investigated for a wide range of materials. ${ }^{1-3}$ These bands form under conditions of high strain rate $\left(>10^{3} \mathrm{~s}^{-1}\right)$ with accompanying large strains. Thus, the temperature of the material will rise during deformation and this rise is a major contributor to obtaining the shear band. Studies of adiabatic shear bands in iron-carbon base materials have been particularly informative because of the phase transformation in steels. The shear bands exhibit high hardness in the order of 10$12 \mathrm{GPa}$. The equivalent tensile strength is 4000 to $4800 \mathrm{MPa}$. Many investigations have centered on analyses of the structure within adiabatic shear bands in bulk $\mathrm{Fe}-\mathrm{C}$ components. ${ }^{1-11}$ Initial studies were on band formation during single step dynamic testing. The bands were known as "white layers" because of their resistance to etching. Similar white layers have been observed in pearlitic rail steel from the continuous impact of the tracks by high-speed trains. ${ }^{12}$ Recently, shear-band formation has been studied through ball milling, through ball-drop tests, and through shot peening of $\mathrm{Fe}-\mathrm{C}$ chips or plates. ${ }^{13-17}$ The fine structures obtained in wire drawing of pearlitic steels ${ }^{18-20}$ are similar to those observed in ballmilling and are obtained under the same conditions, namely high strain rate and adiabatic heating. Severe torsion deformation of pearlitic ultrahigh carbon steel under high-pressure ${ }^{21}$ is also related to shear banding. Most studies generally show a sharp discontinuity in the structure and hardness adjacent to the shear band. These discontinuities are indicative of phase transformation or dynamic recrystallization. ${ }^{22-24}$

Microstructural explanations for the high hardness of the shear bands in Fe-C steels have not been resolved and are the subject of considerable debate. Among the proposed mechanisms are: (a) Ultra-fine martensite from phase transformation, ${ }^{4-7}$ (b) Supersaturated solution of interstitial carbon in body- 
centered-cubic ferrite, ${ }^{18-21,25,26}$ (c) Carbon atoms all residing at dislocation sites, ${ }^{18-20,25}$ (d) Ultra-fine ferrite grains in the order of 10 to $100 \mathrm{~nm}^{7,13-17,20-22,27,28}$ (e) Carbon atoms dissolved in ultra-fine amorphous ferrite grain boundaries, ${ }^{28}$ (f) Ultra fine dislocation cell structure, ${ }^{29,}{ }^{30}$ It would appear that the contribution of nano-carbide particles to the strength of these ultrahigh strength Fe-C steels has been ignored as a strengthening mechanism. Ironically, early mechanisms of deformation for interpreting the strength of high carbon steels were based solely on the presence of carbide particles. The strength of Fe-C steels was shown to be a function of the logarithm of the inter-particle spacing. ${ }^{31-33}$ Ansell $^{34}$ developed a model based on dislocation pile-up at particles and showed that the strength of spheroidized Fe-C steels was a function of the reciprocal square root of the interparticle spacing. Subsequently, Syn et $\mathrm{al}^{35}$ showed that both inter-particle carbide spacing and the ferrite grain size contribute independently to the strength of spheroidized Fe-C steels. Makii et $\mathrm{al}^{36,37}$ showed that the change in strength of a wire-drawn eutectoid steel with annealing was a function of the carbide size. The present investigation will propose that carbide particles are likely major contributors to the ultrahigh hardness observed in many Fe-C steels where adiabatic shear banding has taken place.

A problem in the study of shear bands in iron-carbon alloys is that there is usually no record of the stress-strain-temperature history of the material prior to or subsequent to shear banding. The compression equipment used in the present investigation allowed for recording the stress, strain and strain rate history of the sample from the start of deformation to the point where adiabatic shear banding occurred. The microstructure in the adiabatic shear band region, together with analysis of the temperature history, suggests an alternative interpretation for the high strength of shear bands in $\mathrm{Fe}-\mathrm{C}$ steels.

\section{MATERIAL AND EXPERIMENTAL PROCEDURE}

The material selected for study was ultra-high carbon steel (UHCS). By prior designation these UHCSs are hypereutectoid steels with carbon content from 1.0 to $2.1 \%$ carbon. ${ }^{38,39}$ A thirty-kilogram ingot, processed by vacuum induction melting, was made of the following composition: $1.3 \% \mathrm{C}, 3.0 \% \mathrm{Si}$, $0.5 \% \mathrm{Mn}, 0.99 \% \mathrm{Cr}$ and balance iron. The ingot was processed by forging at $1090^{\circ} \mathrm{C}$ from a square cross-section, $125 \mathrm{~mm}$ wide, to a plate $25 \mathrm{~mm}$ thick by $100 \mathrm{~mm}$ wide. It was noted that a small amount of discontinuous graphite stringers was present in the as-forged plate induced by the graphitizing influence of silicon. The plate was then homogenized for one hour at $1125^{\circ} \mathrm{C}$ and air-cooled. This treatment produced a fully pearlitic structure.

Samples for compression testing were prepared in the form of right circular cylinders, $6.35 \mathrm{~mm}$ in diameter and $6.35 \mathrm{~mm}$ tall. All samples were deformed in the same direction as the plate lengthening direction during the forging operation. The hardness showed a VHN $=3.55 \mathrm{GPa},\left(\mathrm{R}_{\mathrm{C}}=36\right)$.

Dynamic compression tests were performed using the split Hopkinson pressure bar technique. The steel sample was placed between two long bars made of Ti-6Al-4V. A striker bar is propelled toward one of the pressure bars (the input bar). Upon impact, an elastic stress wave is introduced into the input bar and the stress wave travels down the bar. At the specimen-bar interface, a portion of this wave is transferred into the sample, causing the sample to deform. The strain histories for the incident and transmitted waves in the elastic pressure bars were measured and analyzed to determine the stress, strain and strain rate response of the sample. 


\section{RESULTS}

\subsection{Stress-strain curves}

Stress-strain curves for the pearlitic sample are shown in Fig. 1. The average strain rate is in the order of $4000 \mathrm{~s}^{-1}$. Fig. 1(a) shows the curve as engineering stress-engineering strain and Fig. 1(b) shows the curve as true stress- true strain. The pearlitic UHCS showed high compression ductility. The engineering stress-strain curve (Fig 1a) shows the engineering stress to increase with straining, with the stress decreasing at $\mathrm{e}=-0.55$ where shear banding was initiated. The true stress-true strain curve (Fig.1b) shows a region of strain hardening up to $\varepsilon=-0.15$ followed by strain softening. The strainsoftening region is a direct consequence of adiabatic heating. A temperature rise of $300^{\circ} \mathrm{C}$ was calculated on the assumption that all of the work of deformation is converted to heating the sample. The true fracture strain was slightly above -0.80 . The load began to drop precipitously from the initiation of shear banding and the test was terminated by a ring stop that limited the total true strain to -0.90 . Compression tests were repeated and the tests confirmed reproducibility of the results.

\subsection{Structure of shear band in pearlitic UHCS.}

Fig. 2 illustrates the initial and deformed states of the pearlitic UHCS sample. The cross-section of the sample prior to testing is given in Fig. 2(a). The matrix consists of a structure of fine pearlite containing a small amount of minute vertical graphite stringers. The stringers are oriented parallel to the lengthening direction during prior forging. Fig. 2 (b) shows a cross-section of the deformed pearlitic sample illustrating the two adiabatic shear bands oriented at about $45^{\circ}$ to the compression axis. Discontinuous cracks are observed within the two shear bands. The width of the adiabatic shear band is $14 \mu \mathrm{m}$.
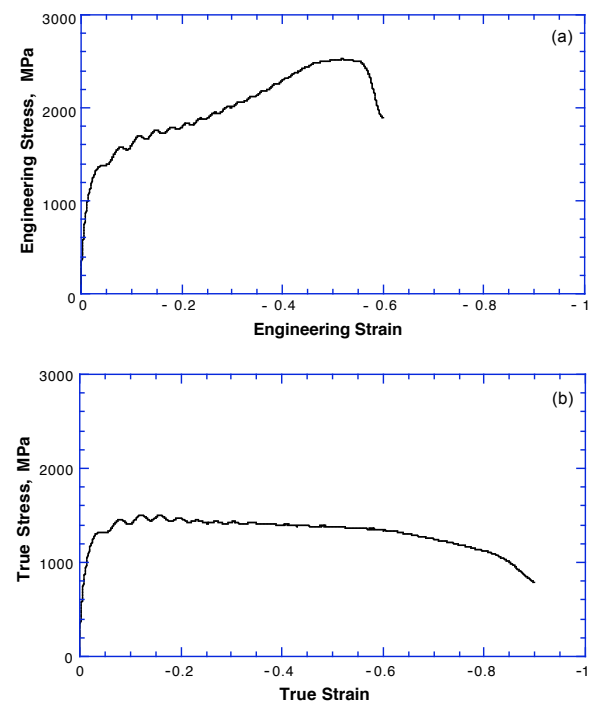

Fig. 1. Stress-strain curves for the pearlitic ultrahigh carbon steel deformed in compression at a strain rate of $4000 \mathrm{~s}^{-1}$ at room temperature. (a) Engineering stress - engineering strain curve and (b) true stress - true strain curve.

SEM photomicrographs taken in the secondary electron imaging mode are shown that illustrate the major structural features within and adjoining the adiabatic shear band. Fig. 3 shows an overview of the shear band imaged originally at 3000X magnification. The pearlite plates bordering the band are highly deformed and strongly oriented in the shear band direction. A piece of graphite is noted within the shear band. Graphite pieces,

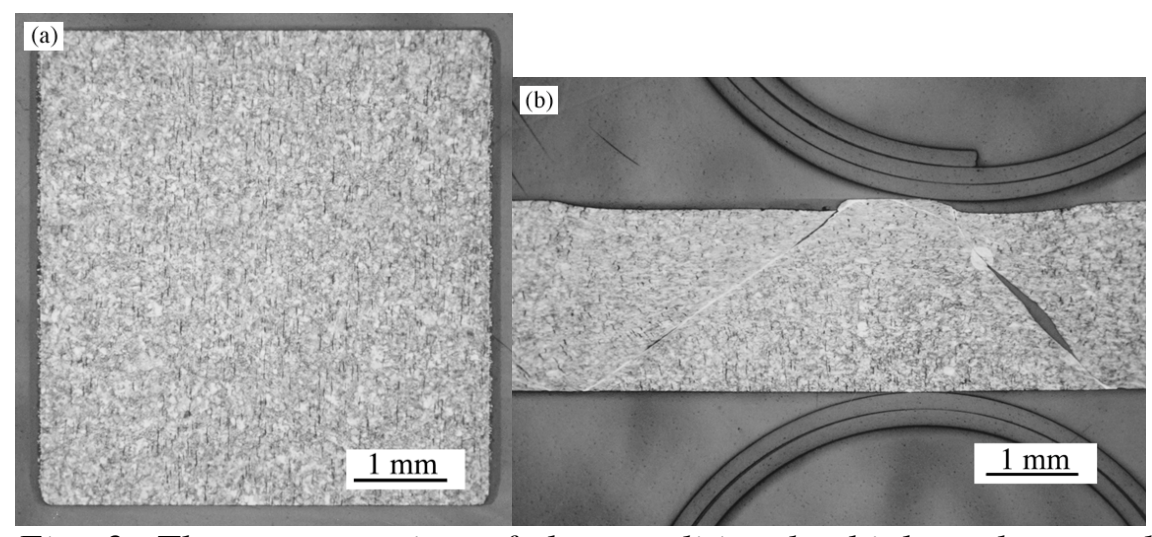

Fig. 2. The cross section of the pearlitic ultrahigh carbon steel sample in the (a) initial state and (b) fractured state. 
originally oriented vertically in the photograph, were dragged into the shear band and deformed within the band. The original diameter of the graphite stringers is about $6 \mu \mathrm{m}$ whereas the stringers in the shear band are about $2.5 \mu \mathrm{m}$. The calculated deformation strain in the graphite is $\varepsilon$ $=\ln (6 / 2.5)^{2}=1.75$. This value of the strain in the shear band is a minimum estimate. This is because the graphite stringer must first reorient itself into the shear band before its full participation in the plastic flow process.

An additional estimate can be calculated of the strain in the band from an observation of the offset of the shear band shown in Fig. 2 (b). The left-hand section of the deformed sample is displaced from the center section, with a length difference of $0.125 \mathrm{~mm}$ along the shear line. A

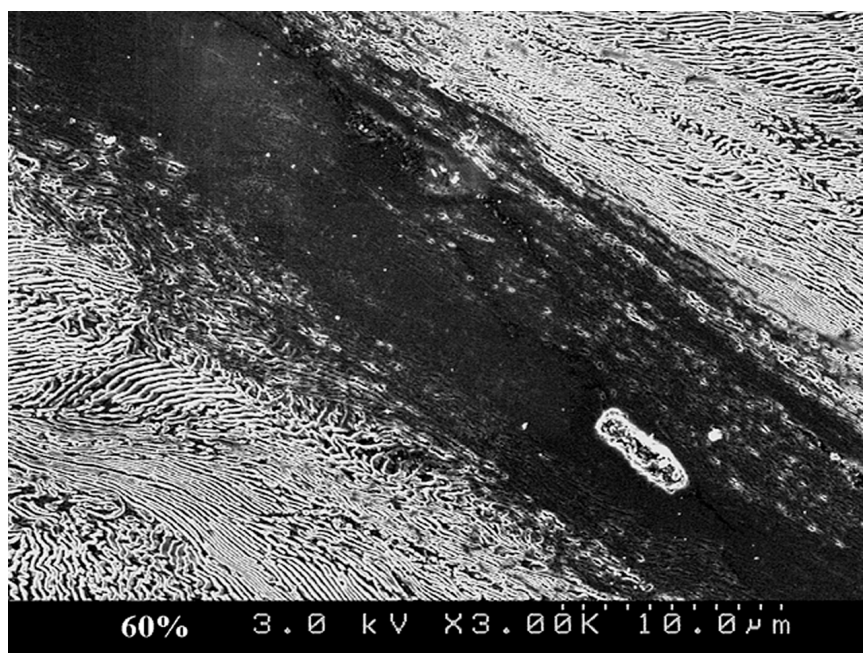

Fig. 3. SEM photomicrograph of the adiabatic shear band in the pearlitic steel illustrating the fine pearlite structure adjoining the band and the graphite stringer trapped within the band. shear strain, $\gamma$, in the band is estimated by dividing this displacement by the shear band width $(14 \mu \mathrm{m})$ yielding $\gamma=11$. The calculated true strain (Von Mises) in the shear band is $\varepsilon=-6.4$. The total true strain in the band is -6.4 plus the strain prior to the start of shear banding $(\varepsilon=-0.8)$ yielding $\varepsilon=-7.2$. This true strain value is similar to those estimated for shear bands in other Fe-C materials. ${ }^{5,9,16}$ The strain rate in the shear band is estimated as follows. The axial strain during shear banding is 0.044 (the axial displacement of $0.125 \mathrm{~mm}$ divided by the sample height of $2.86 \mathrm{~mm})$, giving a time of shear banding of $1.1 \times 10^{-5} \mathrm{~s}(0.044$ divided by 4000$)$. Thus the strain rate in the shear band is the strain in the band (-6.4) divided by the deformation time in the band yielding a strain rate of $6 \times 10^{5} \mathrm{~s}^{-1}$. Such a strain rate is often quoted in studies of high velocity projectiles and high explosive charges. ${ }^{40,41}$

Fig. 4 shows a high magnification microstructure of the center of the shear band shown in Fig. 3. A fine structure is observed with nanostructure features in the order of $70 \mathrm{~nm}$. In agreement with other investigators, ${ }^{16,17,21}$ these features are the ferrite grain size. The outer bounds of the shear band reveal

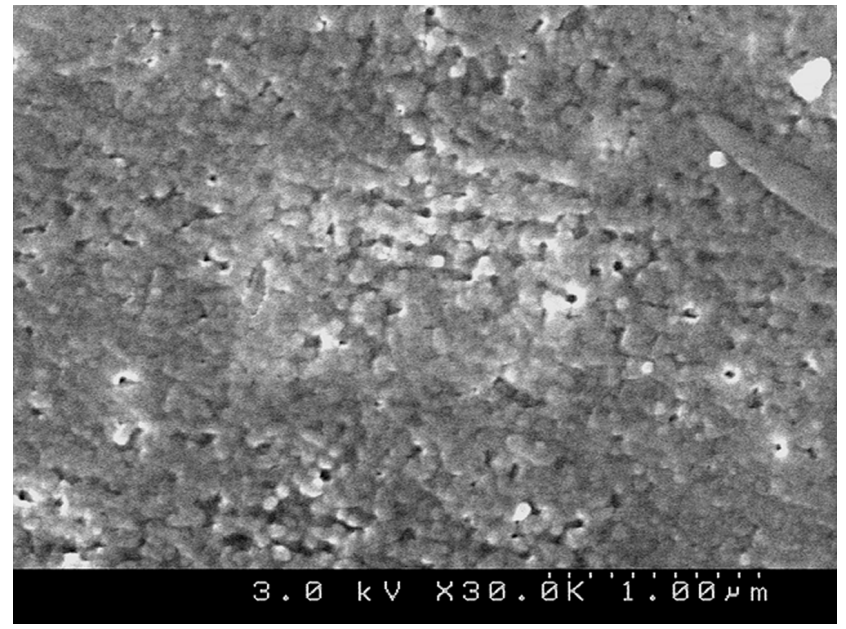

Fig. 4. High magnification SEM photomicrograph illustrating the ultra fine ferrite structure in the center of band shown in Figure 3.

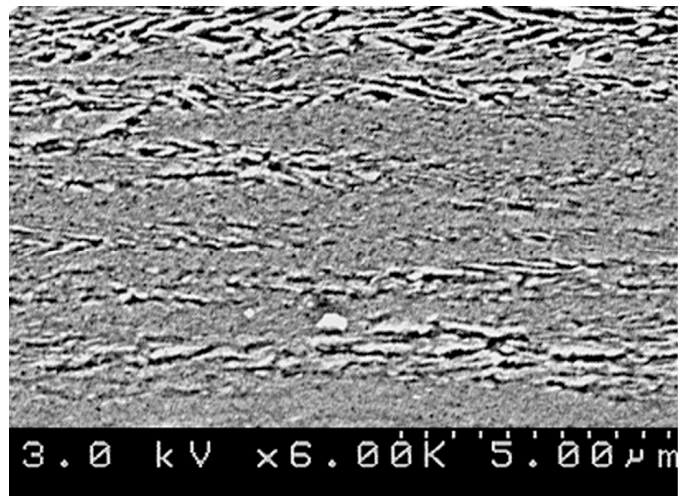

Fig. 5. SEM photomicrograph illustrating the outer edge of the adiabatic shear band where a mixture of an ultrafine-structure and pearlite co-exist. 
unusual structures and an example is shown in Fig. 5. A mixture of two structures appears. Segmented, broken-up regions (much like that observed in the center of the band) are mixed with oriented pearlite regions. The lamellar spacing in the pearlite remains about the same throughout this unique region. This multi-structure region is a clue for understanding the processes occurring during shear banding and is described in the discussion section.

\subsection{Nanohardness of the shear band}

Hardness measurements were made with a nano-indenter. Fig. 6 shows the result of a nano-hardness traverse. The indentation sizes were about $200 \mathrm{~nm}(0.2 \mu \mathrm{m})$. It can be seen that the hardness values recorded in the adiabatic shear zone gave an average value of $11 \mathrm{GPa}$ with a maximum value of $11.5 \mathrm{GPa}$. The hardness of the pearlite adjoining the shear band is $6.5 \mathrm{GPa}$. The high hardness obtained in the shear band cannot be achieved by deformation under conditions of isothermal working. For example the tensile strength of severely cold-rolled pearlitic UHCSs is $2500 \mathrm{MPa}^{42}$ This is equivalent to a nano-hardness of $6.3 \mathrm{Gpa}^{43}$ The result indicates that adiabatic shear, involving a temperature rise during deformation, is a requirement for ultrahigh strength.

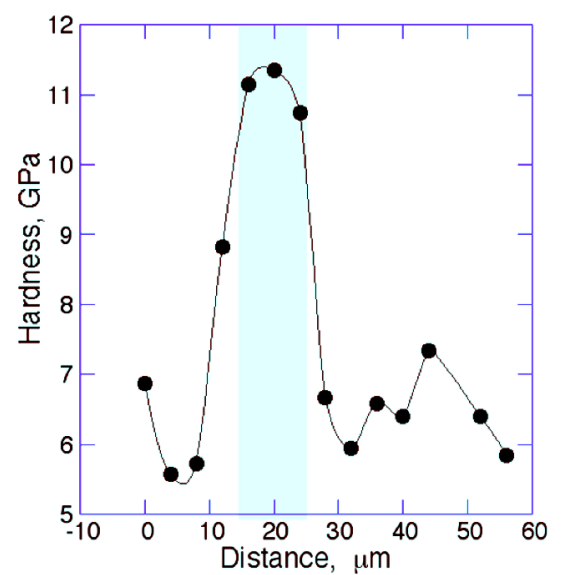

Fig. $\quad 6 . \quad$ Nano-indentation hardness measurements of the adiabatic shear band region for the ultrahigh carbon steel.

\section{DISCUSSION}

In order to understand the structure of the adiabatic shear band, it is necessary to consider transformations that could take place. Specifically, we consider that adiabatic heating was sufficient to produce a temperature in the shear band in excess of the eutectoid transformation temperature. Transformation to austenite occurs and subsequent rapid cooling creates the observed ultrafine structure.

\subsection{Phase equilibria in UHCS-3Si.}

In order to understand the structure of the band depicted in Fig. 5, it is necessary to understand the phase diagram for the $1.3 \% \mathrm{C}$ steel containing $3 \% \mathrm{Si}^{44,45}$ The pearlite structure remains stable up to about $800^{\circ} \mathrm{C}$ at which temperature much of pearlite transforms to austenite. This is the eutectoid transformation temperature. Not all of the cementite will dissolve, however, because three phases coexist: namely, austenite, with some ferrite and cementite as undissolved pearlite. Upon further heating, pearlite will progressively decrease in amount to about $880^{\circ} \mathrm{C}$, the ferrite will disappear and only austenite and cementite remain. At about $1050^{\circ} \mathrm{C}$, all the cementite will dissolve in the austenite. This is the $\mathrm{A}_{\mathrm{cm}}$ point. Above $1050^{\circ} \mathrm{C}$ the $\mathrm{UHCS}-3 \% \mathrm{Si}$ will remain austenitic with further heating until incipient melting occurs.

\subsection{Estimation of the temperature rise during deformation}

The proposed stress-strain-temperature history from adiabatic heating is shown in Fig. 7. The temperature of $300^{\circ} \mathrm{C}$ is shown at a strain of -0.8 where the flow stress is about $1200 \mathrm{MPa}$. This is the strain where the shear band is created. The flow stress is shown to decrease linearly with further straining. The decrease was guided by the known strength of a UHCS deformed at high temperature at high strain rate of $1000 \mathrm{~s}^{-1} .{ }^{46}$ This study showed the flow stress to be $500 \mathrm{MPa}$ at $730^{\circ} \mathrm{C}$. These values are located at a true strain of -2.8 based on the work of deformation fully converting to heat. Subsequent 
straining shows continued decrease in the flow stress followed by an increase in strength at about $800^{\circ} \mathrm{C}$. The eutectoid transformation temperature for the UHCS-3\% Si material begins at this temperature. The small strength increase is because austenitic UHCS is stronger than ferritic UHCS. ${ }^{47}$ The strength of the austenitic UHCS will decrease as the temperature continues to increase. The strength is estimated to be $200 \mathrm{MPa}$ at a true strain of $\varepsilon=-$ 7.2. ${ }^{47,} 48$ The calculated temperature

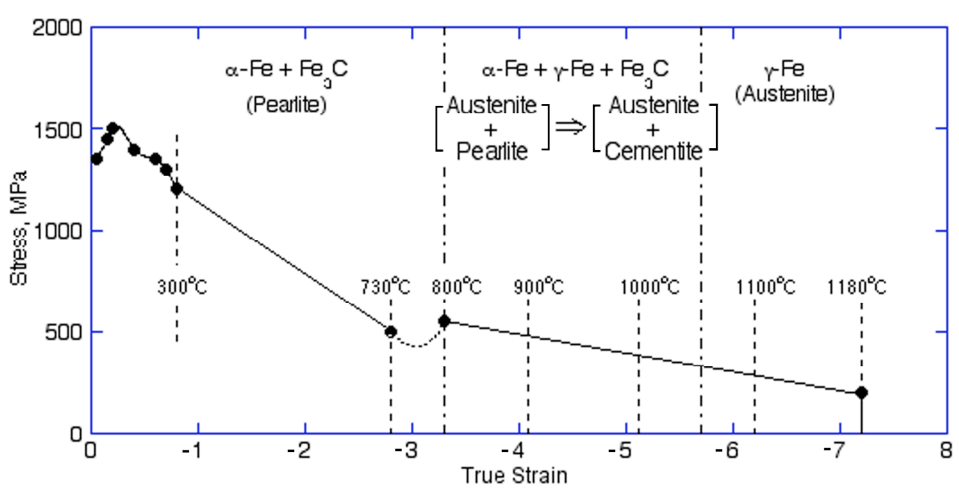

Fig. 7. Proposed stress-strain-temperature history of the pearlitic ultra-high carbon steel $(1.3 \% \mathrm{C}-3 \% \mathrm{Si})$. increase within the band from the work of deformation yields a final temperature of $1180^{\circ} \mathrm{C}$. Upon completion of deformation the shear band will experience a rapid quench since the band is bonded to a much lower temperature material (i.e. $\left.300^{\circ} \mathrm{C}\right)$.

\subsection{Nanocarbides by severe plastic deformation accompanied by a divorced eutectoid transformation}

The hardness of the shear band is extraordinarily high, $11.5 \mathrm{GPa}$. This is equivalent to a yield strength of $4600 \mathrm{MPa}(667 \mathrm{ksi})$. We propose that the high strength is a result of the severe deformation of the ultrahigh carbon steel during heating in the ferrite and austenite range and to a divorced eutectoid transformation (DET) at the end of shear banding. We define the divorced eutectoid transformation as a transformation that is divorced of all normal transformations including transformations that produce pearlite, bainite and martensite. The structural changes are best described in three stages: (i) deformation in the ferrite range, up to $\varepsilon=-3.2$, (ii) deformation in the range containing austenite, $\varepsilon=-$ 3.2 to -7.2 and (iii) quenching upon termination of deformation.

In the first stage of deformation, the pearlite spacing is decreased, with simultaneous decrease in the cementite plate thickness. By a true strain of $\varepsilon=-3.2$ (a reduction of 25 to 1 ), the plate thickness is estimated to be in the order of $2-5 \mathrm{~nm} .{ }^{49}$ The cementite plates will develop dislocation substructures and break up into nano-size entities. Such changes have been observed in wire drawn pearlitic steels deformed to comparable strains in the adiabatic shear band. ${ }^{18-20,50-52}$ The amount of carbon in solution in ferrite at the transformation temperature is $0.02 \% \mathrm{C}^{53}$ The second stage begins with the transformation of ferrite iron to face-centered-cubic gamma iron. It is an athermal process, i.e. essentially instantaneous. The gamma iron will contain the same amount of carbon in solution as in ferrite $(0.02$ wt. \%C). There is no time for carbon diffusion into the gamma iron lattice. This is because of the high strain rate in the shear band, $\dot{\varepsilon}=6 \times 10^{5} \mathrm{~s}^{-1}$ with a resulting time in austenite of $10^{-5} \mathrm{~s}$. The broken up carbide plates will deform in the gamma iron matrix with iron penetration between the carbide particles. At the end of the second stage, the carbide size can be expected to be in the order of 1-2 nm. The third stage involves re-transformation of gamma iron containing nano-carbides to ferrite iron. The cooling rate is estimated at $10^{6}{ }^{\circ} \mathrm{C} \mathrm{s}^{-1} .{ }^{9}$. The gamma to ferrite transformation is athermal, and the nano-carbides will remain fine, quite similar to the size at the end of the second stage. The ferrite may retain $0.02 \mathrm{wt}$ $\% \mathrm{C}$.

The transformation steps described above have striking similarity to the traditional divorced eutectoid transformation (DET) resulting from bulk thermal-mechanical processing, ${ }^{54-57}$ but has significant 
differences. The traditional DET depends on the rate of a moving boundary that separates the disappearing austenite from the newly formed structure consisting of carbide particles and ferrite. ${ }^{56}$ Creating a traditional DET structure is dependent on the diffusion rate of carbon in austenite to deposit on any pre-existing un-dissolved carbides. The present DET process involves a diffusion-less transformation from FCC austenite (mainly gamma iron plus carbides) to BCC ferrite (mainly alpha iron plus carbides). There is no significant time for carbon atom migration or carbide particle dissolution. No retained austenite is expected.

The present proposal that phase transformation takes place in adiabatic shear bands in Fe-C steels has support from evidence that the fine ferrite grain size varies widely ranging from 5 to $100 \mathrm{~nm}$. ${ }^{7,13-17,20-22,27}$, 28 This is because the grain size of the transformed ferrite is dependent on a number of factors. The variables that need consideration are the prior austenite grain size, the initial ferrite grain size and the amount of deformation in each phase. In addition, the possibility for repetitive deformation and transformation events can influence the final grain size. Thus, multi-transformations as in deformation by ball milling leads to nano-ferrite grain sizes (less than $20 \mathrm{~nm}$ ), ${ }^{13-15,17,20,22,27,28}$ whereas single transformations lead to ferrite grain sizes that are over $50 \mathrm{~nm}^{7,}{ }^{16,21}$ The second evidence for phase transformation is from the microstructure shown in Figure 5. This region is at the outer edge of the shear band in the temperature range where two phases co-existed, a gamma iron matrix with layered carbides containing gamma iron (that is, a pearlitic structure of gamma iron and carbide). Upon retransformation these layers became pearlite again, although somewhat mottled, surrounded by nanoferrite grains.

\subsection{Influence of carbides and grain boundaries on the strength of $\mathrm{Fe}-\mathrm{C}$ steels}

Many studies have shown that fine particles can be a dominant source of strengthening. The finer the particles, i.e. the smaller the inter-particle spacing, at constant volume fraction, the higher the strength. 31-35 This then leads to the possibility that the strength of the nano-ferrite structures may be controlled by the presence of nano-size carbides, and not by the ferrite grain size alone. Syn et $\mathrm{al}^{35}$ showed that the flow stress of spheroidized carbon steels $(0.5$ to $1.8 \% \mathrm{C})$ can be predicted from microstructural observations through the following relation:

$$
\sigma=310\left[\mathrm{D}_{\mathrm{S}}^{*}\right]^{-0.5}+460[\mathrm{~L}]^{-0.5}
$$

where $\mathrm{D}_{\mathrm{S}} *$ is the surface-to-surface carbide particle spacing, and $\mathrm{L}$ is the ferrite grain size. The flow stress is given in units of MPa with $\mathrm{D}_{\mathrm{S}}{ }^{*}$ and $\mathrm{L}$ in units of $\mu \mathrm{m}$. The particle spacing, $\mathrm{D}_{\mathrm{S}}{ }^{*}$, is a function of the volume fraction of carbides and the particle diameter as follows:

$$
\mathrm{D}_{\mathrm{S}} *=[3 / 2]^{0.5 \cdot}\left\{\left[\pi /\left(4 \mathrm{f}_{\mathrm{V}}\right)\right]^{0.5}-1\right\} \cdot \mathrm{d}
$$

where $f_{V}$ is the volume fraction and $d$ is the particle diameter. A modification of Eq. (1) has been proposed by Taleff et al that considers the case of carbides existing as plates, i.e. pearlite. ${ }^{58}$

Eq. (1) is based on the independent contribution of carbides and grain boundaries to the strength. That is, carbide particles and grain boundaries are considered as separate and independent obstacles to plastic flow. It is identical to the Hall-Petch relation where the yield strength is predicted from the additive contributions of grain boundaries (where $\mathrm{k}_{\mathrm{Y}}=460$ ) and matrix (the $\sigma_{0}$ term). In the case of Fe-C steels the matrix contribution is principally from carbide particle strengthening and is given as $310\left[\mathrm{D}_{\mathrm{S}} *\right]^{-0.5}$ in Eq. (1). Thus the $\sigma_{0}$ term can be a variable in the modified Hall-Petch relation rather than a constant as is often assumed. 
Many Fe-C steels have been processed to develop nano-size ferrite grains. These ultrafine grains were produced by ball-milling, ball-drop, and dynamic impact methods (torsion and compression). They all exhibit very high hardnesses. A seeming anomaly regarding the strength- grain size relation for these $\mathrm{Fe}-\mathrm{C}$ steels is illustrated in Fig. 8, where the yield strength is plotted as a function of grain size. The nano-ferrite grain size $\mathrm{Fe}-\mathrm{C}$ materials are illustrated by filled symbols $(0.005$ to $0.1 \mu \mathrm{m})$ at the top section of the figure. This graphically illustrates that there is no grain-size dependence. In contrast, a Hall-Petch type relation is observed and shown for four iron-base materials processed by traditional casting and mechanical working procedures. Among these, the lowest strength material is a Swedish iron that was processed to purge all the interstitial atoms. ${ }^{59}$ The data, covering the grain size range from $100 \mu \mathrm{m}$ down to $20 \mu \mathrm{m}$, represents the true grain size effect on the strength of iron. The strength is in excellent agreement with the strength prediction from Eq. (1) given by the dashed line in Fig. 8. Aged mild steel, studied by Hall ${ }^{60}$ in the grain-size range from $50 \mu \mathrm{m}$ down to $7 \mu \mathrm{m}$ is stronger than Swedish iron as a result of the presence of interstitial carbon and iron carbides. Additional data ${ }^{61,62}$ for an $\mathrm{Fe}-$ $0.18 \% \mathrm{C}$ is also plotted in Fig. 8. These data covers the range from $9 \mu \mathrm{m}$ down to $0.4 \mu \mathrm{m}$, and were obtained through dilute additions of $\mathrm{W}$ and $\mathrm{Zr}$. The spheroidized ultrahigh carbon steels (1.5 and $1.8 \%$ $\mathrm{C})$, tested in the grain size range from $5 \mu \mathrm{m}$ down to $0.3 \mu \mathrm{m}$, are the strongest of the four cast-processed materials. These data, with other Fe-C steels, ${ }^{35}$ is the basis of developing the relation given as Eq. 1.

An explanation of the unexpected breakdown of the Hall-Petch relation for the ultra-fine grain size materials has been suggested by Takaki et al. ${ }^{27,}{ }^{28}$ They state that "some stress accommodation mechanisms works at grain boundary and this contribution becomes effective in the grain size region below $0.1 \mu \mathrm{m}$ ". An important source of stress accommodation is through grain boundary sliding that will reduce dislocation pile-up at grain boundaries. This is because the grain boundaries are high angle boundaries and the fine grain size promotes extensive grain boundary activity. The break-down of the Hall-Petch relation for the $0.18 \mathrm{C}$ steel below $4 \mu \mathrm{m}$ (Fig. 8) can also be explained by the contribution of grain boundary sliding to decreasing the effect of dislocation pile-up strengthening.

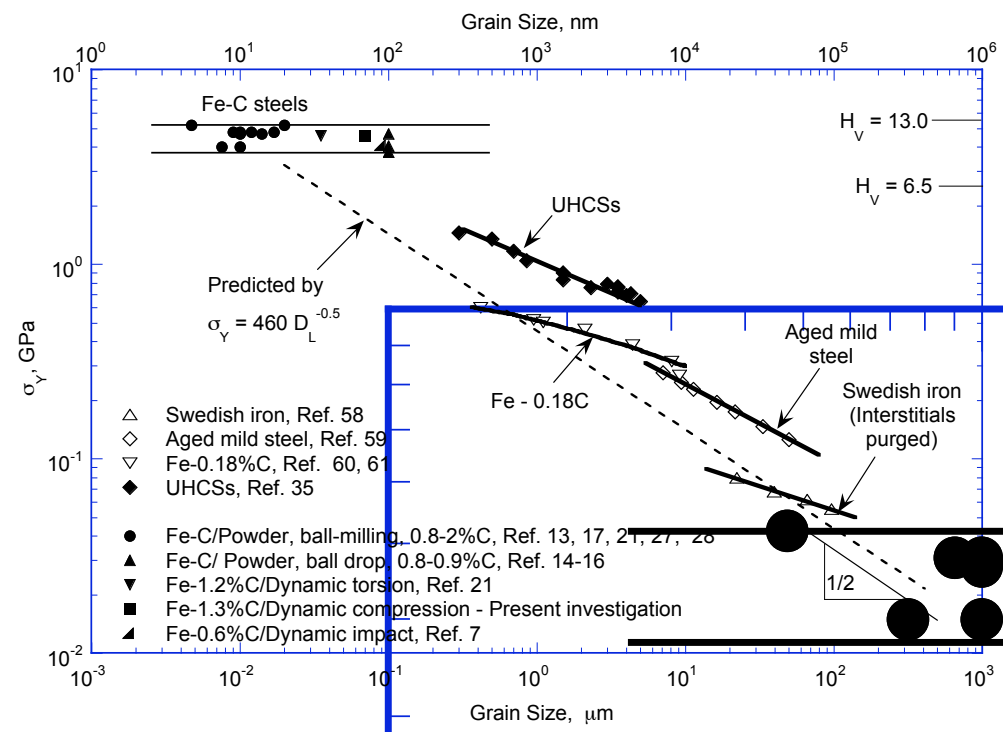

Fig. 8. Grain size vs yield strength of selected iron-base materials. The Vickers hardness numbers, $H_{V}$, are shown on the right hand side for values above $6 \mathrm{GPa}$. The theoretical relation between $H_{V}$ and $\sigma_{Y}$ is given by $H_{V}=$ $C \cdot \sigma_{Y}$ where $C=3$. The value of $C$ selected, however, was 2.5 because experimental studies by Jia et $\mathrm{al}^{43}$ obtain this constant at high values of hardness $\left(H_{V}>6 \mathrm{GPa}\right)$. At lower values of hardness, Belyakov et al showed $C$ equal to $3 .^{63}$

An estimate can be made of the carbide size in the adiabatic shear band of the $1.3 \% \mathrm{C}$ UHCS material. On the assumption that the grain size is not contributing to the strength, Eq. (1) predicts the yield strength to be equal to $310\left[\mathrm{D}_{\mathrm{S}}{ }^{*}\right]^{-0.5}$. With $\mathrm{H}=11.5 \mathrm{GPa}\left(\sigma_{\mathrm{Y}}=4600 \mathrm{MPa}\right)$, the value of $\mathrm{D}_{\mathrm{S}}{ }^{*}$ is equal to 
$0.0045 \mu \mathrm{m}(4.5 \mathrm{~nm})$. From Eq. (2), with $\mathrm{f}_{\mathrm{V}}=0.21$, the carbide particle diameter, $\mathrm{d}$, is predicted to be 1.5 $\mathrm{nm}$. This is a small size and that explains why these small particles have not been readily detected.

\subsection{Evidence for nano-carbides in Fe-C steels}

The divorced eutectoid transformation model predicts a structure consisting of very fine carbide particles distributed uniformly within the nano-ferrite grains. The exact nature of these fine carbides, that is the composition, could be different from the stable $\mathrm{Fe}_{3} \mathrm{C}$. Other reported carbides include the Hagg carbide $\left(\mathrm{Fe}_{5} \mathrm{C}_{2}\right)$, and carbides with composition $\mathrm{Fe}_{\mathrm{x}} \mathrm{C}$, where $\mathrm{x}=1,2,4,6,8,23$. $^{53,64}$ Amorphous $\mathrm{Fe}_{3} \mathrm{C}$ has also been identified. ${ }^{65}$ It is known that $\mathrm{Fe}_{2} \mathrm{C}$, and carbon as diamond, are in equilibrium with ferrite at low temperature. ${ }^{66-68}$ The nano-carbide particles could have special properties. For example, they may be paramagnetic and not ferromagnetic in the same way that epsilon martensite is not ferromagnetic. $^{69}$

Our arguments for the presence of nano-carbides are primarily from deductive analyses and secondarily from direct observations. The deductive analysis centers on the question - where are the carbon atoms located? There are four places where they can be located: as interstitial atoms in the bcc ferrite matrix, as carbon atoms dissolved in the grain boundary, as carbon atoms attached to dislocations, and as carbides in the matrix and/or the grain boundary. It will be shown that the presence of nano-carbides is more likely than for carbon atoms in the other locations.

The case for carbon supersaturation in the bcc matrix is not compelling. Lattice parameter studies of ball-milled Fe-C steels by Hidaka et $\mathrm{al}^{28,70}$ reveal that no more than $0.1 \mathrm{wt} \% \mathrm{C}$ exists in the ferrite of the ball-milled eutectoid composition Fe-C powders. Therefore, the remainder of the carbon (i.e $0.7 \mathrm{wt}$ $\% \mathrm{C}$ ) must reside elsewhere. The possibility of the segregation of carbon to the grain boundary has been considered unlikely ${ }^{22}$. This is because 3D atom-probe analysis show a uniform distribution of carbon atoms rather than non-uniform distribution as would result from segregation at grain boundaries. ${ }^{20}$ The likelihood of dislocation - carbon atom strengthening is considered to be small in most cases because of the low dislocation density that is observed. ${ }^{16}$ A conclusion is that carbon in the form of discrete nanosize particles must exist within the matrix of ferrite grains.

One of the most thorough studies of microstructural changes during wire-drawing is that of Hono et al ${ }^{20}$ on a $0.97 \% \mathrm{C}$ steel. Their results give support for a DET type process during wire drawing. These researchers showed a "drastic change" in the structure from $\varepsilon=-3.6\left(\sigma_{\mathrm{Y}}=3840 \mathrm{MPa}\right)$ to $\varepsilon=-5.1\left(\sigma_{\mathrm{Y}}=\right.$ $5170 \mathrm{MPa}$ ). Field ion micrographs showed a "lamellar contrast" of ferrite and cementite at $\varepsilon=-3.6$, but by a strain of 5.1 a "uniform contrast" was observed. The sudden change in structure is readily explained by adiabatic shear banding, followed by phase transformation involving the DET process. The "uniform contrast" is likely the presence of nano-carbides. The authors noted, from lattice parameter measurements, a low concentration of carbon dissolved in ferrite similar to those noted by Hidaka et al. ${ }^{28,70}$. These results, together with the work of Hong et al, ${ }^{19}$ indicate that the "uniform contrast' structure may consist of a homogeneous distribution of carbide particles of a size predicted by Eqs. (1) and (2).

The presence of nano-carbides may not be able to explain, however, the high strength of low carbon iron wires. An example is the case of Scifer wires, a development of Kobe Steel. The composition is $0.2 \mathrm{wt} \% \mathrm{C}, 1.2 \mathrm{wt} \% \mathrm{Si}, 1.5 \mathrm{wt} \% \mathrm{Mn}$, balance iron. The tensile strength of a $7 \mu \mathrm{m}$ diameter wire is 5300 MPa. Bhadeshia and Harada ${ }^{30}$ have indicated that $0.1 \mathrm{wt} \% \mathrm{C}$ is in solution for such a wire. Therefore, only $0.1 \mathrm{wt} \% \mathrm{C}$ is available to form carbides. Assuming that the carbide diameter is $1.5 \mathrm{~nm}$, with the volume fraction $\mathrm{f}_{\mathrm{V}}=0.016$ (for $0.1 \mathrm{wt} \% \mathrm{C}$ ), the value of $\mathrm{D}_{\mathrm{S}}^{*}$ from Eq. (2) is $20.98 \mathrm{~nm}(0.02098 \mu \mathrm{m})$. Eq. 
(1) predicts a yield strength of $2140 \mathrm{MPa}$. This is less than half of the actual strength. The remaining strength probably arises from the dislocation cell structure that is observed in Scifer as observed by Bhadesia and Harada.

\section{SUMMARY AND CONCLUSIONS}

It is shown that the structure of adiabatic shear bands in a pearlitic ultrahigh carbon steel $(1.3 \% \mathrm{C})$ is the result of phase transformation. The hardness of the band is $\mathrm{H}=11.5 \mathrm{GPa}$ and the ferrite grain size is 70 $\mathrm{nm}$. Adiabatic heating leads to transformation to austenite with retransformation to ferrite through a divorced eutectoid transformation (DET). The resulting structure is predicted to consist of a finegrained ferrite matrix containing nanometer size carbides. A modified Hall-Petch relation, that incorporates a particle strengthening term, is shown to predict the strength of shear banded structures in ball-milled Fe-C steels. The results of this study, yield the following conclusions:

(1) It is proposed that phase transformation accompanied by DET occur in Fe-C steels under high strain rate conditions.

(2) Nano-ferrite structures in eutectoid composition Fe-C steels obtained by ball-milling and by ball drop tests are formed by shear bands involving a (DET).

(3) The exceptionally high strength (5000 MPa) of a pearlitic steel obtained by Hono et al during wire drawing at a high strain of $\varepsilon=5.1$ is likely the result of a DET.

(4) The nano-carbide particle size in the $1.3 \% \mathrm{C}$ steel is predicted to be $1.5 \mathrm{~nm}$.

(5) The high strength of $\mathrm{Fe}-\mathrm{C}$ steels, in the hardness range of 10 to $13 \mathrm{GPa}$, is likely a result of nanocarbides rather than that of the fine grain size and of carbon dissolution in ferrite.

\section{ACKNOWLEDGEMENTS}

The authors acknowledge the collaboration of Dr. Dong Wha Kum of the Korean Advanced Institute for Science and Technology, South Korea, for providing the ultrahigh carbon steel ingot used in the present study. The assistance of Dr. Andrea Hodge in the nanoindentation study is sincerely appreciated. Professor William Nix, Stanford University provided much appreciated insight on strengthening mechanisms and nanohardness measurements of shear bands. The experiments were done under the auspices of the U.S. Department of Energy, under Contract No. W-7405-Eng-48 at UC, Lawrence Livermore National Laboratory.

\section{REFERENCES}

[1] Y. Bai and B. Dodd: 'Adiabatic Shear Localization', 1992, Oxford, UK, Pergamon Press

[2] T. W. Wright: 'The Physics and Mathematics of Adiabatic Shear Bands', 2002, Cambridge University Press

[3] M. Stelly and R. Dormeval: in 'Metallurgical Applications of Shock-Wave and High-Strain-Rate Phenomena', (ed. L. E. Murr et al), 607, 1986, New York, Marcel Dekker.

[4] H. C. Rogers: in 'Deformation, Processing and Structure', (ed. G. Krauss), 425, 1984, Metals Park OH, ASM

[5] C. Zener and J. H. Hollomon: J. Appl. Physics, 1944, 15, 31

[6] P. A. Thornton and F. A. Heiser: Metall. Trans., 1971, 2, 1496

[7] R. C. Glenn and W. C. Leslie: Metall. Trans., 1971, 2, 2945

[8] H. C. Rogers and C. V. Shastry CV: in 'Shock Waves and High Strain Phenomena in Metals' (ed. M. A. Meyers and L. E. Murr), 285, 1981, New York, Plenum Press

[9] C. L. Wittman, M. A. Meyers and H-r Pak: Metall. Trans. A, 1990, 21A, 707

[10] A. K. Zurek: Metall. Mater. Trans. A, 1994, 25A, 2483

[11] R. Dormeval and M. Stelly: in 7th Int'1 Conf. on 'High Energy Rate Fabrication', 10, 1981, Univ. of Leeds, UK

[12] S. B. Newcomb and W. M. Stobbs: Mater. Sci. Eng., 1984, 66, 195 
[13] Y. Xu, M. Umemoto and K. Tsuchiya: Mater. Trans., 2002, 43, 2205

[14] M. Todaka, M. Umemoto and K. Tsuchiya: ISIJ (Iron Steel Inst. Japan) Int'l, 2002, 42, 1430

[15] M. Umemoto, B. Hang, K. Tsuchiya and N. Suzuki: Scripta Mater., 2002, 46, 383

[16] M. Umemoto: Mater. Trans., 2003, 44, 1900

[17] M. Umemoto, Z. G. Li, K. Masuyama, X. Hao and K Tsuchiya: Scripta Mater., 2001, 44, 1741

[18] J. Languillaume, G. Kapelski and B. Baudelet: Acta Mater., 1997, 45, 1201

[19] M. H. Hong, W. T. Reynolds, Jr., T. Tarui and K. Hono: Metall. Mater. Trans. A, 1999, 30A, 717

[20] K. Hono, M. Ohnuma, M. Murayama, S. Nishida, A. Yoshie and T. Takahashi: Scripta Mater., 2001, 44, 977

[21] A. V. Korznikov, Yu V. Ivanisenko, I. M. Lapitionok, I. M. Safarov, V. P. Pilyugin and R. Z. Valiev: Nanostructured Mater., 1994, 4, 159

[22] Y. Xu, Z. G. Liu, M. Umemoto and K. Tsuchiya: Metall. Mater. Trans. A, 2002, 33A, 2195

[23] V. F. Nesterenko, M. A. Meyers, J. C. Lasalvia, M. P. Bondar, Y. J. Chen and Y. L. Lukyanov: Mater. Sci. Eng., 1997; A229, 23

[24] M. A. Meyers, V. F. Nesterenko, J. C. Lasalvia and Q. Xue: Mater. Sci. Eng., 2000, A317: 204

[25] V. N. Gridnev, V. V. Nemoshkallenko, Y. Y. Meshkov, V. G. Gavrilyuk, V. G. Prokopenko and O. N. Razumov: Physica Status Solidi, 1975, A31, 201

[26] H. G. Read, W. T. Reynolds, Jr., K. Hono and T. Tarui: Scripta Mater., 1997, 37, 1221

[27] S. Takaki, K. Kawasaki and Y. Kimura Y: J. Mater. Process. Technol., 2001, 117, 359

[28] H. Hidaka, T. Tsuchiyama and S. Takaki: Scripta Mater., 2001, 41, 1503

[29] G. Langford G and M. Cohen: Metall. Trans., 1970, 1, 1478

[30] H. K. D. H. Bhadeshia and H. Harada: Applied Surface Science, 1993, 67, 328

[31] M. Gensamer, E. B. Pearsall, W. S. Pellini and J. R. Low: Trans. ASM, 1942, 30, 893

[32] A. M. Turkalo and J. R. Low: Trans. AIME, 1958, 212, 750

[33] C. T. Liu and J. Gurland: Trans. AIME, 1968, 242, 1535

[34] G. S. Ansell: in 'Physical Metallurgy' (ed. R. W. Cahn), 887, 1965, Amsterdam, North Holland Publ. Co.

[35] C. K. Syn, D. R. Lesuer and O. D. Sherby: Metall. Trans. 1994, 25A, 1481

[36] K. Makii, H. Yaguchi, T. Minamida, M. Kaiso, N. Ibaraki and Y. Oki: Tetsu-to-Hagane (J. Iron Steel Inst. Japan), 1997, 83, 42

[37] K. Makii, H. Yaguchi, M. Kaiso, N. Ibaraki, T. Minamida and Y. Oki: Scripta Mater. 1997, 37, 1753

[38] O.D. Sherby, T. Oyama, D. W. Kum, B. Walser and J. Wadsworth: JOM (J. of Metals), 1985, 37, 50

[39] D. R. Lesuer, C. K. Syn, A. Goldberg, J. Wadsworth and O. D. Sherby: JOM, 1993, 45, 40

[40] A. H. Cottrell: in Proc. Conf. 'The Properties of Materials at High Rates of Strain", 1, 1957, London, Inst. Mech. Engineers.

[41] E. de L. Costello: ibid, p. 13.

[42] S. Tagashira, K. Sakai, T. Furuhara and T. Maki: ISIJ (Iron Steel Inst. Japan) Int'l, 2000, 40, 1149

[43] D. Jia, K. T. Ramesh and E. Ma: Acta Mater., 2003, 51, 3495

[44] O. D. Sherby and T. Oyama: U.S. Patent No. 4,533,390, Aug 6, 1983

[45] C. K. Syn, D. R. Lesuer and O. D. Sherby: in 'Thermomechanical Processing and Mechanical Properties of Hypereutectoid Steels and Cast irons' (ed. D.R. Lesuer et al), 117, 1997, Warrendale, PA, TMS

[46] Z. Rosenberg, D. Dawicke and B. Bless: in 'Metallurgical Applications of Shock Wave and High Strain Rate Phenomena' (ed. L.E. Murr et al), 543, 1986, New York, NY, Marcell Dekker

[47] D. R. Lesuer, C. K. Syn, J. D. Whittenberger, M. Carsi, O. A. Ruano and O. D. Sherby OD: Mater. Sci. Eng., 2001, A317, 101

[48] M. Carsi, A. Fernandez-Vicente, O. A. Ruano and O. D. Sherby: Mater. Sci. Technol., 1999; 15: 1087

[49] D. R. Lesuer, C. K. Syn, O. D. Sherby and D. W. Kum: Materials Science Forum, 2003, 426-432, 841.

[50] G. Langford: Metall. Trans., 1970, 1, 465

[51] G. D. Smith, D. A. Smith and K. E. Easterling: in Proc. ${ }^{\text {rd }}$ Int'l Conf. "The Strength of Metals and Alloys', 75, 1973, Inst. Metals and Iron and Steel Inst., Cambridge, England

[52] J. D. Embury and R. M. Fisher, Acta Metall., 1966, 14, 147

[53] M. Hansen and K. Anderko: in 'Constitution of Binary Alloys', 362, 1958, New York, NY, McGraw-Hill,

[54] T. Oyama, O. D. Sherby, J. Wadsworth and B. Walser: Scripta Metall., 1984, 18, 799

[55] O. D. Sherby, T. Oyama T and J. Wadsworth: U.S. Patent No. 4,448,613, May 15, 1984

[56] J. D. Verhoeven and E. D. Gibson: Metall. Mater. Trans. A, 1998, 29A, 1181

[57] J. H. Whitely: J. Iron Steel Inst., 1922, 105, 339

[58] E. M. Taleff, C. K. Syn, D. R. Lesuer and O. D. Sherby: Metall. Mater. Trans. A, 1996, 27A, 111

[59] R. Armstrong, L. Codd, R. M. Douthwaite and N. J. Petch: Phil. Mag., 1962, 7, 45

[60] E. O. Hall: Proc. Roy. Soc., 1951, B54, 747

[61] V. Ramachandran and E. P. Abrahamson II: Scripta Metall., 1972, 6, 287 
[62] V. Ramachandran and E. P. Abrahamson II: in $4^{\text {th }}$ Int'l Conf. "Strength of Metals and Alloys" (ed. Laboratoire de Physique du Solide - ENSMIM INPL), 1338, 1976, Nancy, France

[63] A. Belyakov, Y. Sakai, T. Hara, Y. Kimura and K. Tsuzaki: Metall. Mater. Trans. A, 2001, 32A, 1769

[64] C-Fe Phase Diagram, in 'Binary Alloy Phase Diagrams', 2nd Ed., 842, 1990, Materials Park (OH), ASM Int'1

[65] T. Nasu, C. C. Koch, K. Nagaoka, M. Sakurai and K. Suzuki: Mater. Sci. Eng., 1991, A134, 1385

[66] E. Lindstrand: Acta Metall., 1958, 3, 431

[67] A. A. Zhukov, L. E. Shterenberg, V. A. Shalashov, V. K. Thomas and N. A. Berezovskaya: Acta Metall., 1973, 21, 195

[68] A. A. Zhukov and R. L. Snezhnoi: Acta Metall., 1973, 21, 199

[69] V. Seetharaman and H. J. Krishnan: Materials Science, 1981, 16, 523

[70] H. Hidaka, T. Tsuchiyama and S. Takaki: Materials Science Forum, 2003, 426-432, 2717 